\title{
An Extended Theory of Planned Behavior (TPB) Used to Predict Smoking Behavior Among a Sample of Iranian Medical Students
}

\author{
Mahmood Karimy ${ }^{1}$; Iraj Zareban ${ }^{2}$; Marzieh Araban ${ }^{3,{ }^{*}}$; Ali Montazeri ${ }^{4}$ \\ ${ }^{1}$ Department of Public Health, Faculty of Health, Saveh University of Medical Sciences, Saveh, IR Iran \\ 2 Department of Public Health, Faculty of Health, Zahedan University of Medical Sciences, Zahedan, IR Iran \\ ${ }^{3}$ Social Determinants of Health Research Center, Ahvaz Jundishapur University of Medical Sciences, Ahvaz, IR Iran \\ ${ }^{4}$ Department Mental Health Research Group, Health Metrics Research Center, Iranian Institute for Health Sciences Research, ACECR, Tehran, IR Iran \\ ${ }^{*}$ Corresponding author: Marzieh Araban, Social Determinants of Health Research Center, Ahvaz Jundishapur University of Medical Sciences, Ahvaz, IR Iran. Tel:+98-9128484191, Fax: \\ +98-6113738269, E-mail: arabanm@ajums.ac.ir
}

Received: October 20, 2014; Revised:January 17, 2015; Accepted: January 25, 2015

\begin{abstract}
Background: Smoking among the youth is an important public health concern. Although several studies have investigated the correlates of smoking behavior, no theory-based study has particularly assessed this problem among medical students.

Objectives: This study aimed to evaluate the efficacy of the extended theory of planned behavior (TPB) to predict smoking behavior among a sample of Iranian medical students.

Patients and Methods: This is a cross-sectional study carried out in Ahvaz, Iran, 2014. The data were collected through a self-administered questionnaire, which included items on demographics, smoking behavior, and components of the TPB model (attitude, subjective norms, perceived behavior control, and intention), and an added construct on smoking refusal skill. Data were analyzed using descriptive correlation, and linear regression statistics by SPSS, version 16.

Results: One hundred and seventy medical students with a mean age of $21.25(\mathrm{SD}=2.9)$ years were enrolled in the study. Of them, $24(13.5 \%)$ students were smokers. All components of the TPB model and smoking refusal skill were statistically significant as to intention to smoke $(\mathrm{P}<0.001)$. The TPB constructs with and without smoking refusal skill accounted for $77 \%$ (adjusted $\mathrm{R} 2$ ) and $78 \%$ of the variance observed for intention to smoke, respectively. The results also revealed the highest weight for perceived behavior control $(\beta=-0.40)$.

Conclusions: The findings of this study indicated that all TPB variables are useful tools for prediction of the smoking behaviors among students. Particularly, students' perceived behavioral control and attitudes towards smoking were found to be important determinants of smoking intentions. Thus, the findings could be used for planning effective tobacco control programs targeting University students.
\end{abstract}

Keywords: Youth; Tobacco; Smoking; Students; Prevention

\section{Background}

While the determinants of health outcomes are complex and diverse, much of the morbidity and mortality burden associated with such diseases are preventable; tobacco smoking is one of the most important contributors to mortality and morbidity in several diseases (1). As the life expectancy improves in developing countries, non-communicable chronic diseases (many of them associated with smoking) are expected to gain greater prominence (2).

Smoking affects all nations; hence, it is a global problem (3). It causes significant harm to individuals' health, particularly as a predisposing factor for coronary heart disease, stroke, respiratory diseases, and various cancers. In addition, it reduces the average life expectancy by 10 years in comparison with nonsmokers (4).

Despite these potential negative outcomes, smoking is a common behavior, especially among young people (5). Young people are at increased risk to start smoking, and college students are no exception (6). Based on recent studies, the prevalence of smoking rises from the first year to the final year among university students (7). Few studies have addressed the impact of school environment on smoking among the youth $(8,9)$. University life could provide a social setting that leads to excessive tobacco usage (10); although tobacco products are readily available to college-aged students, access to tobacco cessation services or preventive measures is limited (11). Moreover, numerous studies have shown that a high proportion of university students are frequently engaged in smoking $(6,12)$.

Based on the results of the world health organization, Nazemi and Chaman (7) has reported prevalence of smoking among young people in the eastern Mediterranean region as follows: $26.6 \%$ in Iran, $20.9 \%$ in Kuwait, 17.2\% in Iraq, $10.1 \%$ in Pakistan, and 15.9\% in Saudi Arabia (7). Also, they showed that the prevalence of smoking among students was $20 \%$ (7). Identification of risk factors for student smoking is a public health priority. Understanding the factors that predict tobacco initiation and 
continuation by college students is vital in designing effective youth cessation programs (13).

However, to explain factors contributing to smoking habits or to design programs to prevent smoking among students, several health education models have been proposed (14). The present study was an attempt to use the theory of planned behavior (TPB) in order to predict smoking behaviors among University students. TPB assumes that the best predictor of a behavior is behavioral intention; intention, in turn, has 3 determinants. The first is the person's attitude towards performing the behavior, which reflects an overall positive or negative evaluation of the behavior (15). Attitude is determined by the individual's beliefs about outcomes or attributes of performing the behavior (behavioral beliefs), and weighted by evaluations of those outcomes or attributes. Secondly, an individual's subjective norm is determined by his or her normative beliefs, that is whether the important referent individuals approve or disapprove of performing that behavior, weighted by his or her motivation to comply with those referents (5). And thirdly, the perceived behavioral control (PBC) refers to the person's perception of the amount of control he or she has over performing the behavior, which is seen to cover the influence of both internal (e.g. refusal skills) and external (e.g. constraints) control factors $(15,16)$.

When Ajzen developed the TPB, it was stated that the TPB is, in principle, open to inclusion of additional predictors as long as they increase the explained variance in behavioral intentions (5). This study used the TPB with an additional construct, namely smoking refusal skills as an additional determinant of behavioral intentions. Previous studies have revealed that refusal skill techniques are important to the competence enhancement approach for preventing smoking and resisting offers to water pipe smoking (17-19). A study by Epstein et al. showed that refusal skill techniques are moderated both perceived social benefits of drinking and friends' drinking for alcohol drinking (17). Obtaining this information is the first step in planning and implementing anti-smoking programs. In Iran previous researches on student smoking have focused mainly on providing the prevalence data and information about the determinants of students' smoking such as access/availability, parent, teacher, and peer's smoking.

\section{Objectives}

In the absence of theory-based research, the aim of this study was to evaluate the efficacy of the extended theory of planned behavior (TPB) to predict smoking behavior among a sample of Iranian medical students.

\section{Patients and Methods}

This was a cross-sectional study carried out on 170 medical students in Ahvaz, Iran. The study used and extended a version of the theory of planned behavior (TPB) as the conceptual framework to assess the predictive power of the TPB constructs on the intention to smoke. The additional construct was smoking refusal skill. The sample size was calculated based on an expected current smoking prevalence of $9 \%$, with absolute precision of $5 \%$. Considering the attrition rate, we enrolled 170 students in the study. The sample size for each gender was estimated on the basis of its proportion. Given that more than $60 \%$ of medical students are female and the rest are male, 114 females and 56 males were selected, using simple random sampling method. Students attending the University campus were approached by the main investigator and after declaring their interest in participating in the study; they received detailed information regarding the aim of the study and were asked to sign the informed consent.

\subsection{Measures}

A self-administered questionnaire was used to collect the data. The questionnaire consisted of 2 parts, including items on sociodemographic variables and TPB constructs. Here, a brief description of the questionnaire is provided

\subsubsection{Demographic Characteristics}

Twenty items were included in the questionnaire to elicit personal information on age, level of study, family members' smoking habits, smoking history, friends' smoking status, age of the first use, and current smoking status.

\subsubsection{Attitude}

Fifteen items on attitude to cigarette smoking, derived from relevant literature (20-22) were included. They were scored using a 5-point Likert differential scale. The scores for each item ranged from 1 (strongly agree) to 5 (strongly disagree).

\subsubsection{Subjective Norms}

Six items were used to assess the influence of the students' important persons (parents, friends, and teachers) on their opinion about smoking. These were scored on a 5-point Likert differential scale, with scores ranging from 1 (strongly agree) to 5 (strongly disagree). Selection of these items was carried out by a panel of scientists affiliated to the department of health.

\subsubsection{PBC to Avoid Smoking}

Seven items were used to assess the students' perceptions about smoking. They were asked to indicate whether it was easy or difficult to smoke. Answers were rated on a 5-point Likert differential scale, ranging from 1 (very difficult) to 5 (very easy for me). PBC questions were derived from published reports.

\subsubsection{Smoking Refusal Skill}

The participants were asked to determine what they 
might do in a situation in which someone offers them a cigarette, with 5 obtainable options: 'I definitely refused,' 'I say: I don't smoke now,' 'I will leave the place,' 'I will say: I have no intention to smoke,' and 'I will change the subject of dialog.' Five answers were rated on a 5-point scale, ranging from 1 (strongly agree) to 5 (strongly disagree).

\subsubsection{Intention}

This section of the questionnaire was derived from the available literature. Seven items were chosen to assess the students' intention or need to smoke cigarettes. For example, it asked 'At any time during the next 3 months do you think you will smoke a cigarette?' or 'If one of your best friends offered you a cigarette, would you smoke it?' Answers were rated on a 5-point Likert differential scale, ranging from 5 (very likely) to 1 (very unlikely). Students' smoking habits and smoking history were investigated as follows: a record of the students' current status of smoking (smoking for $\geq 1$ day during the past 30 days), past cigarette smoking experience, even one or two puffs (ex-smoker) and non-smoker (students who had never smoked). The investigator constructed the questionnaires based on the elicitation results, and the content validity of the instruments was assessed by 10 experts. Content validity ratio (CVR) was 0.85 and content validity index (CVI) was 0.89 . Next, the reliability of the questionnaire was assessed using Cronbach $\alpha$ coefficient, which was moderately high (attitude $=0.94 ; \mathrm{PBC}=0.87$; subjective norms $=0.85$; smoking refusal skill $=0.79$ and intention $=0.87$ ).

\subsection{Ethical Considerations}

The ethics committee of Ahvaz Jundishapur University of Medical Sciences approved the study. Students gave verbal informed consent. To ensure data privacy, the questionnaires were anonymous and they were collected in a box. The box was not opened until the end of the study.

\subsection{Statistical Analysis}

Data were analyzed using SPSS, v.16. Statistical significance was determined at $\mathrm{P}<0.05$ level. Descriptive variables are expressed as frequency, mean, and overall range (minimum and maximum). Scores for constructs of the TPB model, including perceived behavior control, attitude, subjective norms, and smoking refusal skill were also compared among current smokers, ex-smokers, and non-smokers using 1-way analysis of variance (ANOVA). A two-step multiple linear regression analysis was conducted to determine whether refusal skill enhances the prediction power of intentions to smoke beyond that obtained by the TPB alone. The components of the TPB were included in the first step and refusal skill was included in the second step. The normality of data was tested using Kolmogorov-Smirnov test, the histogram, and normality of residuals.

\section{Results}

A total of 170 medical university students participated in this study. Of them $67 \%$ were female and $33 \%$ male. The mean age of the participants was $21.25 \pm 2.9$ (Mean \pm SD) years and the median age was 21 years. The age range was 18 - 25 years. Prevalence of smoking experience, current use, and water pipe (hookah) were $61.4 \%, 36 \%$, and $65 \%$, respectively in males. These rates were $14 \%, 3.5 \%$, and $18.4 \%$, respectively in females. About $14.5 \%$ of students were current smokers. More than two-thirds of the students (76.5\%) reported that cigarette was easy to buy (females (65\%) and males (88\%)). About $28 \%$ of the students, with significantly more boys than girls (49\% versus $6 \%, \mathrm{P}<$ $0.001)$, reported that they might smoke during the next 3 months. As to the reason for continuing smoking, more than $54 \%$ of the students attributed it having fun and $38 \%$ of students to reduction of stress and depression.

According to the results of Spearman correlation analysis, it was found that age $(\mathrm{r}=0.19)$, number of smoking friends ( $r=0.41)$, number of smoking family members $(r=0.37)$, attitude $(\mathrm{r}=0.32)$, perceived behavior control $(\mathrm{r}=0.35)$, and subjective norm $(r=0.29)$ were positively related to the intention of smoking with statistical significance at the 0.05 level. Chi-square test showed that the smoker students were significantly similar to the non-smoker students regarding sociodemographic characteristics such as settlements (urban or rural), pocket money, education level, parental education, and job. But chi-square statistical test results showed a statistically significant difference between the groups of smokers and non-smokers regarding the family members and friends, gender, regular physical activity, grade point average, and hookah use status (Table 1).

Using independent sample t-test, it was found that the mean scores of smoking attitude, subjective norm, PBC, intention, and smoking refusal skills of non-smokers were $49.9,12.3,24.7,9.5$, and 18.3 , respectively while they were $30.6,7.1,18.1,13.5$, and 24.4 for smokers. As shown in Table 2, there was a statistically significant difference in all TPB model components and smoking refusal skills between smokers and non-smokers (Table 2).

As displayed in Table 3, in order to predict the students' intentions to smoking, a multiple linear regression analysis was carried out using the stepwise method. In the first model, attitude, subjective norms, and perceived behavior control were considered as predictors; we found significant effects for attitude $(\beta=-0.40, \mathrm{P}<0.00 \mathrm{l}), \mathrm{PBC}(\beta=-0.38$, $\mathrm{P}<0.001)$, and subjective norm $(\beta=-0.24, \mathrm{P}<0.001)$. This model accounted for $77 \%$ of the variance in intention to smoke. In step 2, smoking refusal skill scale was added to the model. The findings showed that TPB constructs and smoking refusal skill accounted for 78.2\% (adjusted R2) of the variance, indicating an additional $1.2 \%$ to the first model. These variables were found to affect intention to smoke in students. PBC was the strongest determinant in the second step $(\beta=0.40, P<0.001)$, attitude subjective norm, and smoking refusal skill each had significant $\beta$ coefficients ( $\beta=-0.31,-0.23$, and -0.11 , respectively; $\mathrm{P}<0.001$ ). 
Karimy M et al.

\begin{tabular}{|c|c|c|c|}
\hline Variable & Current Smoker $(n=24)$ & Non-Smoker $(n=146)$ & PValue \\
\hline Gender & & & 0.001 \\
\hline Male & $20(36)$ & $36(64)$ & \\
\hline Female & $4(3.5)$ & $110(67.5)$ & \\
\hline Family smoking & & & 0.001 \\
\hline Yes & $15(8.2)$ & $26(15.3)$ & \\
\hline No & $9(5.2)$ & $120(71.3)$ & \\
\hline Friend Smoking & & & 0.001 \\
\hline Yes & $20(11.2)$ & $23(14.2)$ & \\
\hline No & $4(2.2)$ & $123(72.4)$ & \\
\hline Hookah use & & & 0.001 \\
\hline Yes & $21(12)$ & $42(25)$ & \\
\hline No & $3(1)$ & $104(62)$ & \\
\hline Grade point average & & & 0.001 \\
\hline$\leq 15$ & $15(8)$ & $27(16)$ & \\
\hline$\geq 15$ & $9(5)$ & $119(71)$ & \\
\hline
\end{tabular}

a Data are presented as No.(\%).

Table 2. Comparison of Attitude, Subjective Norms, Perceived Behavior Control, Intention, and Smoking Refusal Skill Scores Among Current Smoker and Non-Smoker Groups a

\begin{tabular}{lcccc}
\hline Variable & All $(\mathbf{n}=\mathbf{1 7 0})$ & Current Smoker $(\mathbf{n}=\mathbf{2 3})$ & Non-smoker $(\mathbf{n}=\mathbf{1 4 7})$ & P Value \\
\hline Attitude & $33.4 \pm 5.8$ & $49.9 \pm 8.9$ & $30.6 \pm 8.6$ & 0.001 \\
Subjective norm & $7.8 \pm 4.5$ & $7.1 \pm 4.0$ & $12.3 \pm 5.2$ & 0.001 \\
PBC & $19 \pm 5.3$ & $18.1 \pm 4.8$ & $24.7 \pm 4.8$ & 0.001 \\
Intention & $11.4 \pm 7.3$ & $24.4 \pm 6.7$ & $9.5 \pm 5.1$ & 0.001 \\
Refusal skill & $17.6 \pm 4.5$ & $13.5 \pm 5.6$ & $18.3 \pm 3.9$ & 0.001 \\
\hline
\end{tabular}

${ }^{\mathrm{a}}$ Data are presented as Mean $\pm \mathrm{SD}$.

Table 3. Results of Multiple Linear Regression Analysis

\begin{tabular}{lcccc}
\hline & Unstandardized Coefficients & Standardized $\beta$ & P Value \\
\cline { 2 - 3 } & B & S.E & & $<0.001$ \\
\hline Step 1 & & & -0.40 & $<0.001$ \\
\hline Attitude & 0.27 & 0.03 & -0.38 & $<0.001$ \\
\hline PBC & 1.05 & 0.14 & -0.24 & $<0.001$ \\
\hline Subjective norms & 0.39 & 0.09 & & $<0.001$ \\
\hline Model R2 =76\% & & & -0.31 & $<0.001$ \\
\hline Step 2 & & & -0.40 & $<0.001$ \\
\hline Attitude & 0.21 & 0.04 & -0.23 & $<0.02$ \\
\hline PBC & 1.12 & 0.14 & -0.11 & $<0.001$ \\
\hline Subjective norms & 0.36 & 0.09 & & \\
\hline refusal skill & 0.16 & 0.07 & & \\
\hline Model R2 =78.2\% & & & & \\
\hline
\end{tabular}




\section{Discussion}

According to this study, $14.1 \%$ of the medical students were current smokers. A significant difference was found between males and females (25\% versus $2.6 \%$ ) in this regard. This pattern of smoking in our students is in accordance with that of the previous study of students in Iran. In a study involving university students of Shahroud (7), $20 \%$ of them reported having experienced smoking. Studies conducted on university students of Kerman and Tehran showed this rate to be $22.7 \%$ and $22.1 \%$, respectively. This finding could be important, as the students are future health care providers and are considered as role models for a great number of people. Therefore, even a low percentage of smokers, among medical students who are to serve as a role model, can have a severe negative effect on smoking prevention programs.

The present study intended to expand the theory of planned behavior by inclusion of one additional variable in its model: smoking refusal skill. Although smoking refusal skill improved the predictive validity of original TPB in terms of statistical significance, in fact, the findings from this study showed that this extended model failed to predict intention to smoke more effectively than the original TPB for a clinical use as the previous study concluded that increasing this power about 5\% might provide a rationale for inclusion in the original model (23). Our study found that among all constructs of the model, PBC contributed to this prediction more significantly than attitude and subjective norm. This was expected because PBC plays an important role when the behavior in question is less volitional. Similar findings were also reported in previous studies $(24,25)$. Smoking literature reveals that low $\mathrm{PBC}$ is related to smoking initiation and smoking rate as well as greater difficulty in quitting and/or higher rates of relapse among adolescents (25, 26). Similarly, Norman et al. concluded that the TPB was predictive of intention to quit smoking with perceived control as the most important predictor $(12,27)$. A metaanalysis of 76 TPB studies found that PBC was a significant predictor in 65 of 76 analyses $(5,27)$.

The results of the present study indicated that the mean score of attitude among current smoker students was higher than that of the non-smoker group. In addition, attitude was a significant factor in predicting the intention to smoke cigarette. Similar results have been reported in other applications of the TPB to the prediction of smoking intentions. For example, some studies (28-30) reported that attitude was predictive of smoking intentions. In another study, Baska (31) in Slovakia showed that attitudes towards tobacco use among the adolescents were closely related to their smoking status, i.e. current smokers more frequently reported positive attitudes. These findings are not limited to a short-term period. In a longitudinal study of adolescent smokers, attitude about smoking was predictive of smoking status 3 years later $(32,33)$. Previous studies on smoking behavior have indicated (33) that when students observe the smoking behavior in role models such as parents, friends, teachers, and significant others and find them sociable, they may come to believe that smoking is a good behavior and thus may make a positive attitude towards it; this could increase their intention to smoke. Therefore, implementation of educational tobacco control programs is necessary aiming at correcting the attitude of students towards smoking.

Subjective norms reflect the person's perception of whether or not important people would want him or her to engage in the behavior (24). The findings revealed that subjective norm is less predictive of intention than attitude or PBC. This finding is in line with the results of meta-analyses of the TPB that shows the average subjective norm-intention correlation is significantly weaker than that between both attitude and perceived behavioral control and intention (34). A study by Johnston and White (35) showed that attitude and subjective norm were predictive of binge drinking intentions. Similarly, Lazuras reported subjective norm could significantly predict their intention to smoke (36). Another study conducted in Sudan showed that the influence of friends was the most important factor affecting the smoking behavior (37). For this reason, health care organizations should recognize the important people for the students, including friends, teachers, parents or other close persons, as they have an influence on their intention to smoke.

The results of the present study demonstrated that stronger smoking refusal skill was associated with lower smoking. On the other hand, the mean score of smoking refusal skill among non-smoker students was higher than that of the current smoker groups. Similar findings have also been reported in previous studies. For example, a study on drug refusal skill (17) showed that this refusal skill was a key component of the protective effect of social competence in terms of adolescent substance use. However, several studies have shown that refusal skills training is an important component in effective prevention programs $(10,19)$.

As to the sociodemographic variables, the results of this study showed an association between students' grade point average and smoking. Students with lower grade point average tended to smoke more. Therefore, health care personnel should pay more attention to students who poorly function in their University studies as they may be the high risk group for smoking in future.

Several limitations of this study should be noted as well. First, because this was a school-based study that relied on students' self-reports, the significant relationships among variables may partly reflect shared method variance. Secondly, it was a cross-sectional study; thus, causal relationships could not be inferred. The third, the results of the study may be subjected to social desirability bias. However the bias may be reduced through the applica- 
tion of trained research staff and acceptable executive process.

In sum, this study indicates that TPB variables are a useful tool for prediction of smoking behaviors among students in Iran. More specifically, students' perceived behavior control and attitudes towards smoking were found to be important determinants of smoking intentions. Thus, the findings of this study are useful for the development of effective tobacco control programs targeting university students.

\section{Acknowledgements}

We gratefully acknowledge participants in the study (students) and University staff that the present study would not have been completed without their contribution.

\section{Authors' Contributions}

All authors equally participated in design, implementation, drafting and revision of the manuscript.

\section{Funding/Support}

This study was funded by a grant from department of social determinant of health research center, Ahvaz Jundishapur University of Medical Sciences; the official support from the University was also acknowledged.

\section{References}

1. Miller CL, Hill DJ, Quester PG, Hiller JE. The impact of Australia's new graphic cigarette packet warnings on smokers' beliefs and attitudes. AMJ. 2011;19(3):181-8.

2. Rudatsikira E, Dondog J, Siziya S, Muula AS. Prevalence and determinants of adolescent cigarette smoking in Mongolia. Singapore Med J. 2008;49(1):57-62.

3. Randheer K, Almotairi M, Naeem HA. Anti-smoking environment: a perspective from Murray's psychogenic needs theory. Glob J Health Sci. 2014;6(1):99-106.

4. Cremers HP, Mercken L, Oenema A, de Vries H. A web-based computer-tailored smoking prevention programme for primary school children: intervention design and study protocol. BMC Public Health. 2012;12:277.

5. Karimy M, Niknami S, Hidarnia AR, Hajizadeh I. Intention to start cigarette smoking among Iranian male adolescents: usefulness of an extended version of the theory of planned behaviour. Heart Asia. 2012;4(1):120-4.

6. Rigotti NA, Regan S, Moran SE, Wechsler H. Students' opinion of tobacco control policies recommended for US colleges: a national survey. Tob Control. 2003;12(3):251-6.

7. Nazemi S, Chaman R. Prevalence of smoking among universities students of Shahroud in 2010. Open J Prev Med. 2012;2(2):235-9.

8. Villanti A, Boulay M, Juon HS. Peer, parent and media influences on adolescent smoking by developmental stage. Addict Behav 2011;36(1-2):133-6.

9. Murnaghan DA, Leatherdale ST, Sihvonen M, Kekki P. A multilevel analysis examining the association between school-based smoking policies, prevention programs and youth smoking behavior: evaluating a provincial tobacco control strategy. Health Educ Res 2008;23(6):1016-28.

10. Karimy M, Niknami S, Heidarnia AR, Hajizadeh E, Shamsi M. Refusal self efficacy, self esteem, smoking refusal skills and water pipe (Hookah) smoking among iranian male adolescents. Asian Pac J Cancer Prev. 2013;14(12):7283-8.
11. Wechsler H, Kelley K, Seibring M, Kuo M, Rigotti NA. College smoking policies and smoking cessation programs: results of a survey of college health center directors. J Am Coll Health 2001;49(5):205-12.

12. Norman P, Armitage CJ, Quigley C. The theory of planned behavior and binge drinking: assessing the impact of binge drinker prototypes. Addict Behav. 2007;32(9):1753-68.

13. Costa FM, Jessor R, Turbin MS. College student involvement in cigarette smoking: the role of psychosocial and behavioral protection and risk. Nicotine Tob Res. 2007;9(2):213-24.

14. Glanz K, Rimer BK, Viswanath K. Health Behavior and Health Education: Theory, Research, and Practice. Wiley; 2008.

15. Hukkelberg SS, Hagtvet KA, Kovac VB. Latent interaction effects in the theory of planned behaviour applied to quitting smoking. BrJ Health Psychol. 2014;19(1):83-100.

16. Travlos A, Kalokairinou A, Sachlas A, Zyga S. Predictors of Smoking and Alcohol Use Behaviour in Undergraduate Students: Application of the Theory of Planned Behaviour. Int J Caring Sci. 2014;7(2):477.

17. Epstein JA, Botvin GJ. Media resistance skills and drug skill refusal techniques: What is their relationship with alcohol use among inner-city adolescents? Addict Behav. 2008;33(4):528-37.

18. Rise J, Sheeran P, Hukkelberg S. The role of self - identity in the theory of Planned behavior: A meta - analysis. J Appl Soc Psychol. 2010;40(5):1085-105.

19. Smith DC, Tabb KM, Fisher D, Cleeland L. Drug refusal skills training does not enhance outcomes of African American adolescents with substance use problems. J Subst Abuse Treat. 2014;46(2):274-9.

20. Amin TT, Amr MA, Zaza BO, Suleman W. Harm perception, attitudes and predictors of waterpipe (shisha) smoking among secondary school adolescents in Al-Hassa, Saudi Arabia. Asian Pac J Cancer Prev. 2010;11(2):293-301.

21. Harakeh Z, Scholte RH, Vermulst AA, de Vries H, Engels RC. Parental factors and adolescents' smoking behavior: an extension of The theory of planned behavior. Prev Med.2004;39(5):951-61.

22. Mallia C, Hamilton-West K. Smoking-related attitudes and perceptions among young adults in Malta and the UK. Psychol Health Med. 2010;15(3):347-56.

23. Karimy M. Using an extended theory of planned behavior (TPB) to predict smoking behavior [thesis]. Tehran: Tarbiat Modares University; 2013.

24. Shi Y, Ehlers S, Warner DO. The theory of planned behavior as applied to preoperative smoking abstinence. PLoS One 2014;9(7):e103064.

25. Minnix JA, Blalock JA, Marani S, Prokhorov AV, Cinciripini PM Self-efficacy mediates the effect of depression on smoking susceptibility in adolescents. Nicotine Tob Res. 2011;13(8):699-705.

26. Karimy M, Niknami S, Heidarnia AR, Hajizadeh I, Montazeri A Prevalence and determinants of male adolescents' smoking in iran: an explanation based on the theory of planned behavior Iran Red Crescent Med J. 2013;15(3):187-93.

27. Norman P, Conner M, Bell R. The theory of planned behavior and smoking cessation. Health Psychol.1999;18(1):89-94.

28. Bledsoe LK. Smoking cessation: an application of theory of planned behavior to understanding progress through stages of change. Addict Behav. 2006;31(7):1271-6.

29. Droomers M, Schrijvers CT, Mackenbach JP. Educational differences in the intention to stop smoking: explanations based on the Theory of Planned Behaviour. Eur J Public Health. 2004;14(2):194-8.

30. Dohnke B, Weiss-Gerlach E, Spies CD. Social influences on the motivation to quit smoking: main and moderating effects of social norms. Addict Behav. 2011;36(4):286-93.

31. Baska T, Sovinova H, Nemeth A, Przewozniak K, Warren CW, Kavcova E, et al. Findings from the Global Youth Tobacco Survey (GYTS) in Czech Republic, Hungary, Poland and Slovakia--smoking initiation, prevalence of tobacco use and cessation. Soz Praventivmed. 2006;51(2):110-6.

32. Engels RC, Van Zundert RM, Kleinjan M. Smoking cessation-specific parenting and parental smoking as precursors of adolescent smoking cognitions and quitting. Addict Behav. 2012;37(7):831-7. 


\section{Karimy M et al.}

33. Engels RC, Hale W3, Noom M, De Vries H. Self-efficacy and emotional adjustment as precursors of smoking in early adolescence. Subst Use Misuse. 2005;40(12):1883-93.

34. Armitage CJ, Conner M. Efficacy of the Theory of Planned Behavour: a meta-analytic review. Br J Soc Psychol. 2001;40(Pt 4):471-99.

35. Johnston KL, White KM. Binge-drinking: A test of the role of group norms in the theory of planned behaviour. Psychol Health.
2003;18(1):63-77.

36. Lazuras L, Eiser JR, Rodafinos A. Predicting Greek adolescents intentions to smoke: a focus on normative processes. Health Psychol. 2009;28(6):770-8.

37. El-Amin Sel T, Nwaru BI, Ginawi I, Pisani P, Hakama M. The role of parents, friends and teachers in adolescents' cigarette smoking and tombak dipping in Sudan. Tob Control. 2011;20(2):94-9. 